УДК 632.78/.914 (477.75)

(C) 2012

Лебедев С. Н., кандидат сельскохозяйственных наук

Южный филиал Национального университета биоресурсов и природопользования Украины «Крымский агротехнологический университет»

\title{
ПРОГНОЗ РАЗМНОЖЕНИЯ ВРЕДОНОСНЫХ ПОКОЛЕНИЙ ГРОЗДЕВОЙ ЛИСТОВЕРТКИ В УСЛОВИЯХ РАВНИННО-СТЕПНОГО КРЫМА
}

\section{Рецензент - доктор сельскохозяйственных наук А. М. Изотов}

Наводяться дані про залежність розвитку шкідливих поколінь тронової листовійки на виноградних насадженнях рівнинно-степового Криму від абіотичних чинників: середньодобової температури повітря, суми опадів, відносної вологості повітря, а також площі листової поверхні куща винограду. На основі ичих даних розроблені математичні моделі прогнозу розвитку фітофага, щзо дадуть змогу оптимізувати кратність і своєчасність захисних заходів у боротьбі з зазначеним шкідником на конкретному сорті винограду.

Ключевые слова: гроздевая листовертка, математическая модель прогноза, виноград.

Постановка проблемы. Немаловажную роль в системах защиты растений играет прогноз, позволяющий заблаговременно судить о фитосанитарном состоянии посевов и насаждений.

Прогноз является основанием для планирования и разработки современных систем интегрированной защиты сельскохозяйственных культур от комплекса вредителей и болезней, расчета потребности в химических, биологических и других средствах защиты растений.

При его разработке рассчитываются объемы мероприятий по защите сельскохозяйственных культур от вредителей, болезней и сорняков. Прогноз позволяет оптимально и в необходимые сроки рассчитать начало защитных работ, количество трудовых затрат, технического оборудования для проведения мероприятий защиты растений от вредителей и болезней, а также финансовые ресурсы.

Для разработки прогноза важной является динамика численности и видовой состав вредителей, их распространения на территории страны, зоны, области, района, хозяйства. Необходимо иметь данные: какие сельскохозяйственные культуры заселяются и повреждаются, степень развития и вредоносность основных видов болезней, а также фитофага [1].

Анализ основных исследований и публикаций, в которых рассматривается проблема. Математические модели долгосрочного прогноза составляют с целью обоснования текущего планирования и своевременной организации защиты растений. Для разработки моделей используют агроэкологические предикторы - агрометеорологические факторы: годовая сумма осадков, средняя годовая температура воздуха, количество дней солнечного сияния в часах, относительная влажность воздуха, а также динамика численности фитофага.

Согласно разработанным моделям с высокой достоверностью прослеживается зависимость динамики численности вредителей сельскохозяйственных культур от колебаний погоды, что и является основным критерием при разработке математических моделей прогноза численности вредителей в условиях разных грунтовоклиматических зон Украины [2].

За рубежом в последние годы были разработаны модели и компьютерные программы, позволяющие прогнозировать развитие сельскохозяйственных культур и сигнализировать о необходимости применения пестицидов [3, 4]. Создание таких программ требует наличия значительного объема данных о развитии вредителей в отдельном регионе за длительный период. Так, например, одной из компьютерных моделей является программа Bugoff G, разработанная в США и применявшаяся в Германии [8]; в Англии применялся программный комплекс PEST-MAN [9].

Цель и задачи исследований. Целью исследований является изучение особенностей и механизмов формирования энтомокомплексов и оптимизация систем защиты виноградных насаждений от доминирующих вредителей в основных микроклиматических зонах Крыма с применением ресурсосохраняющих технологий получения экологически чистой продукции. В задачи исследований входило: 1) установить динамику численности фитофагов в зависимости от абиотических и биотических факторов; 2) определить физиологические, фенологические, межструктурные и математические зависимости исследуемых видов насекомых от факторов внешней среды; 3) разработать матема- 
тические модели краткосрочного и долгосрочного прогнозов численности основных фитофагов в регионах исследований.

Материалы и методики исследований. В 2004-2010 гг. проводили мониторинг численности гроздевой листовертки на виноградных насаждениях в условиях равнинно-степного Крыма по общепринятым методикам [6, 7]. Математические модели прогноза численности фитофага разрабатывали с помощью корреляционно-регрессионного метода [5].

Результаты исследований. В годы исследований на сорте Молдова прослеживается зависимость появления каждого поколения гроздевой листовертки от климатических условий и площади листовой поверхности куста (см. табл.). При этом была установлена тесная корреляционная связь развития первого поколения, глав- ным образом, со среднесуточной температурой воздуха, суммой осадков и площадью листовой повехности куста. Характерно, что разработанная нами модель (1) позволяют с точностью более $80 \%$ прогнозировать как появление, так и развитие первого поколения на сорте Молдова в равнинно-степном Крыму (рис. 1).

Математическая модель 1 :

$$
\mathrm{y}_{1}=268,133-19,313 \cdot \mathrm{X}_{1}-0,01 \cdot \mathrm{X}_{2}+3,43 \cdot \mathrm{X}_{4} \text {, }
$$

где: $\mathrm{Y}_{1}$ - прогнозируемая численность листовёртки первого поколения в текущем году, экз./ловушку;

268,133 - коэффициент согласования единиц;

$\mathrm{X}_{1}$ - показатель среднесуточной температуры воздуха, ${ }^{\circ} \mathrm{C}$;

$\mathrm{X}_{2}-$ показатель суммы осадков, мм;

$\mathrm{X}_{4}$ - площадь листовой поверхности куста, м $^{2}$.

Фактическая и прогнозированная численность гроздевой листовертки на сорте Молдова в условиях равнинно-степного Крыма (2004-2010 г2.)

\begin{tabular}{|c|c|c|c|c|c|c|c|c|c|c|}
\hline \multirow{2}{*}{\multicolumn{4}{|c|}{ Показатели }} & \multicolumn{7}{|c|}{ Годы } \\
\hline & & & & \multirow{2}{*}{$\begin{array}{l}2004 \\
12,6\end{array}$} & \multirow{2}{*}{$\begin{array}{l}2005 \\
11,9\end{array}$} & \multirow{2}{*}{$\begin{array}{l}2006 \\
11,1\end{array}$} & \multirow{2}{*}{$\begin{array}{l}2007 \\
12,7\end{array}$} & \multirow{2}{*}{$\begin{array}{l}2008 \\
11,8\end{array}$} & \multirow{2}{*}{$\begin{array}{l}2009 \\
12,3\end{array}$} & \multirow{2}{*}{$\begin{array}{c}2010 \\
13,5\end{array}$} \\
\hline \multicolumn{3}{|c|}{ температура воздуха, ${ }^{\circ} \mathrm{C}$} & $\mathrm{X}_{1}$ & & & & & & & \\
\hline \multicolumn{3}{|c|}{ Сумма осадков, мм } & $\mathrm{X}_{2}$ & 607 & 495 & 420 & 344 & 452 & 636 & 1074,4 \\
\hline \multicolumn{3}{|c|}{$\begin{array}{c}\text { Относительная влажность } \\
\text { воздуха, \% } \\
\end{array}$} & $X_{3}$ & 75,7 & 70,8 & 73,8 & 65,6 & 71,7 & 73,2 & 74,7 \\
\hline \multicolumn{3}{|c|}{$\begin{array}{c}\mathrm{S} \text { листовой поверхности } \\
\text { куста, } \mathrm{m}^{2}\end{array}$} & $\mathrm{X}_{4}$ & 9,234 & 9,3 & 8,532 & 9,247 & 9,752 & 9,258 & 9,348 \\
\hline \multirow{6}{*}{ 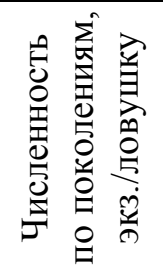 } & \multirow{2}{*}{1} & факт. & & 45 & 81 & 75 & 51 & 62 & 61 & 44 \\
\hline & & прогн. & $\mathrm{y}_{1}$ & 50,19 & 65,09 & 78,68 & 51,02 & 69,02 & 55,98 & 28,73 \\
\hline & \multirow{2}{*}{2} & факт. & & 84 & 82 & 90 & 84 & 68 & 85 & 75 \\
\hline & & прогн. & $\mathrm{y}_{2}$ & 81,25 & 80,13 & 93,09 & 81,03 & 72,50 & 80,84 & 79,32 \\
\hline & \multirow{2}{*}{3} & факт. & & 54 & 35 & 48 & 31 & 19 & 31 & 39,41 \\
\hline & & прогн. & $y_{3}$ & 44,10 & 34,53 & 54,16 & 26,70 & 27,51 & 43 & 40,26 \\
\hline
\end{tabular}

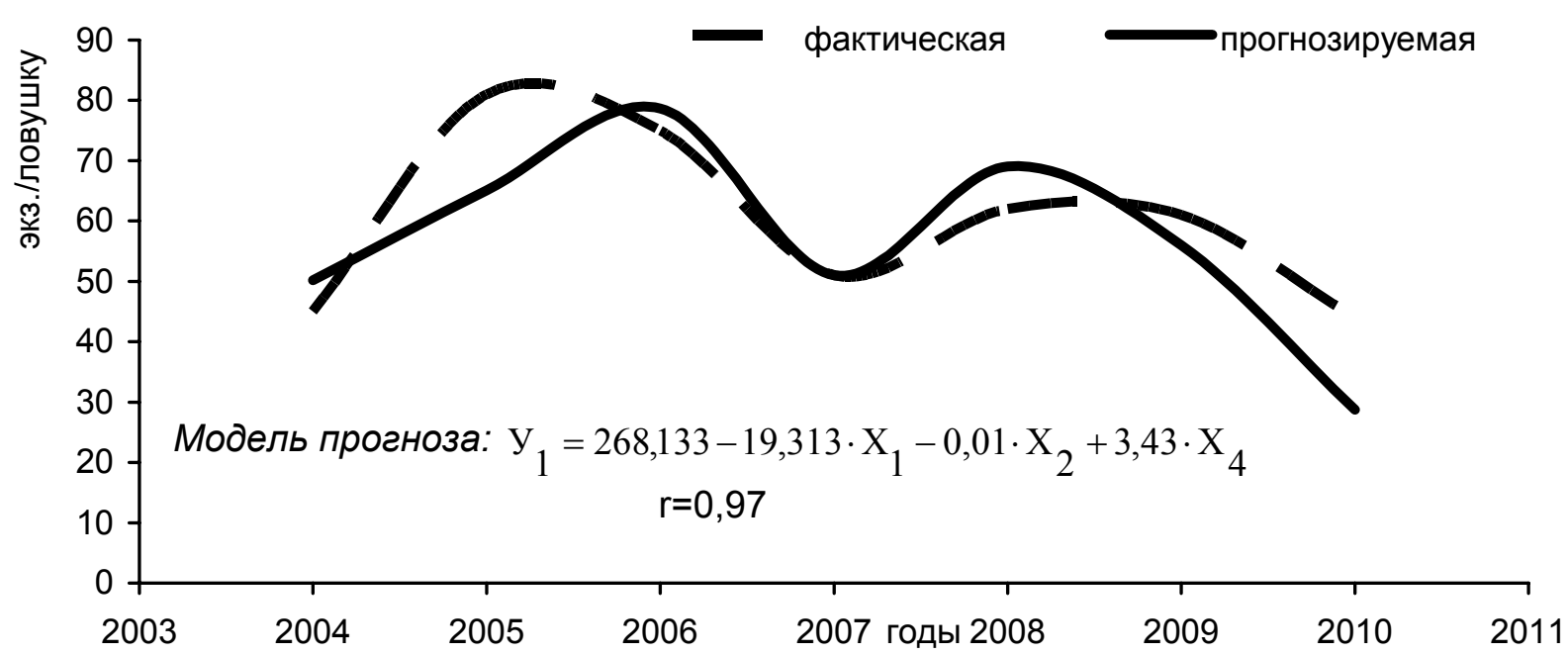

Рис. 1. Динамика численности первого поколения гроздевой листовертки в условиях равнинно-степного Крыма (сорт Молдова, в среднем за 2004-2010 z2.) 


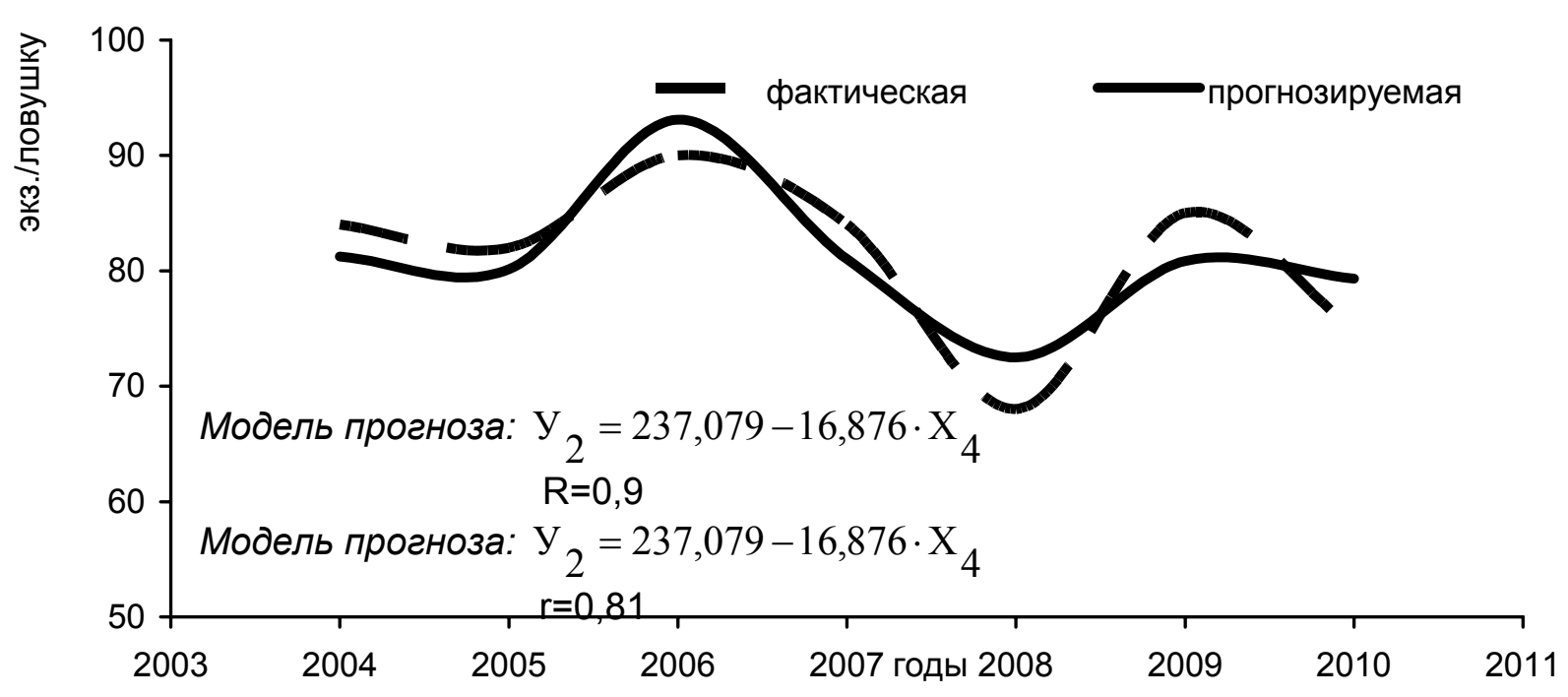

Рис. 2. Динамика численности второго поколения гроздевой листовертки в условиях равнинно-степного Крыма (сорт Молдова, в среднем за 2004-2010 г2.)

Появление и развитие второго поколения гроздевой листовертки на этом же сорте было тесно связано с площадью листовой поверхности куста. Прогноз численности данного фитофага во втором поколении дает возможность определить количественные показатели вредителя по одному предиктору с коэффициентом корреляции 0,81 :

Математическая модель 2:

$$
\mathrm{y}_{2}=237,079-16,876 \cdot \mathrm{X}_{4},
$$

где: $\mathrm{У}_{2}$ - прогнозируемая численность листовёртки второго поколения в текущем году, экз./ловушку;

237,079 - коэффициент согласования единиц;

$\mathrm{X}_{4}$ - площадь листовой поверхности куста, ${ }^{2}$.

Установлено, что численность гроздевой листовертки в третьем поколении находилась в тесной корреляционной связи с относительной влажностью воздуха и площадью листовой поверхности куста. Согласно нашей модели (3), численность фитофага в третьем поколении можно прогнозировать с точностью до $70 \%$ (рис. 3):

Математическая модель 3:

$$
\mathrm{y}_{3}=90,171+1,699 \cdot \mathrm{X}_{3}-18,916 \cdot \mathrm{X}_{4}
$$

где: У третьего поколения в текущем году, экз./ловушку;

90,171 - коэффициент согласования единиц;

$\mathrm{X}_{3}$ - показатель относительной влажности воздуха, \%;

$\mathrm{X}_{4}$ - площадь листовой поверхности куста, $\mathrm{m}^{2}$.

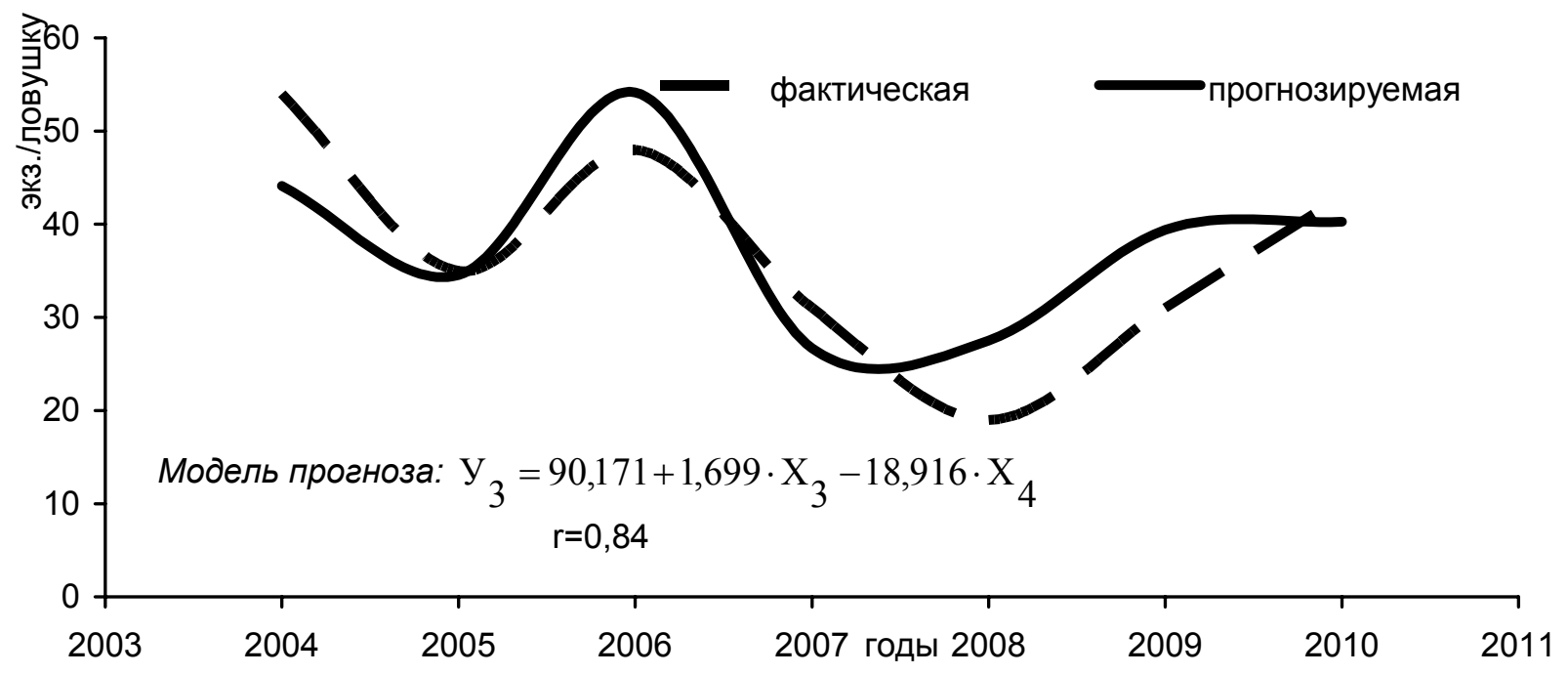

Рис. 3. Динамика численности третьего поколения гроздевой листовертки в условиях равнинно-степного Крыма (сорт Молдова, в среднем за 2004-2010 г2.) 
Выводы. Установлена тесная корреляционная зависимость развития вредоносных поколений гроздевой листовертки и абиотических факторов, в результате чего были разработаны математические модели прогноза численности фитофага, позволяющие на конкретном сорте (в данном случае Молдова) прогнозировать этапы онтогенеза вредителя в условиях равнинно-

\section{БИБЛИОГРАФИЯ}

1. Довгань С. В. Рекомендації щодо застосування моделі прогнозу розвитку та розмноження лучного метелика в Степу України / С. В. Довгань. Херсон: Айлант, 2008. - 12 с.

2. Довгань С. В. Рекомендації щодо застосування моделі прогнозу розвитку та розмноження озимої совки в Степу України / С. В. Довгань. Херсон: Айлант, 2008. - 12 с.

3. Довгань С. В. Моделі прогнозу розвитку та розмноження фітофагів / С. В. Довгань. Херсон: Айлант, 2009. - 207 с.

4. Довгань С. В. Методологія оцінки впливу коливань погоди на розмноження основних шкідливих видів довгоносиків України / С. В. Довгань. - Вінниця: Кормовиробництво, 2009. № 65 . - C. 171-173.

5. Доспехов Б. А. Планирование полевого опыта степного Крыма с точностью 84-97\%. Полученные результаты дают возможность оптимизировать кратность, а также своевременность применения защитных мероприятий, эффективно подбирать препараты с действующим веществом и препаративной формой. Это способствует оптимизации использования материальных и финансовых ресурсов хозяйств.

и статистическая обработка его данных / Б. А. Доспехов. - М.: Колос, 1972. - 206 с.

6. Методики випробування і застосування пестицидів / С. О. Трибель, Д. Д. Сігарьова, М. П. Секун [та ін.]; за ред. С. О. Трибеля. - К.: Світ, 2001. - 428 с.

7. Фітосанітарний моніторинг / М. М. Доля, Й. Т. Покозій, Р. М. Мамчур [та ін.]. - К.: ННЦ IAE, 2004. - $294 \mathrm{c}$.

8. Blago N. "Bugoff $2 \mathrm{G}$ " the adaptation of a Californian model for the codling moth to the Central European conditions / N. Blago // Acta Phytopatologica et Entomologica hungarica. - 1992. 27 (1-4). - P. 119-125.

9. Morgan D. PEST-MAN: a forecasting system for apple and pear pests / D. Morgan, M.G. Solomon // EPPO Bulletin. - 1993. - 23. - P. 601-605. 